\title{
A Moment Magnitude Scale
}

\author{
Thomas C. Hanks \\ U.S. Geological Survey, Menlo Park, California 94025 \\ Hiroo KaNAMORI \\ Seismological Laboratory, California Institute of Technology, Pasadena, California 91125
}

\begin{abstract}
The nearly coincident forms of the relations between seismic moment $M_{0}$ and the magnitudes $M_{L}$, $M_{s}$, and $M_{w}$ imply a moment magnitude scale $. M=f \log M_{0}-10.7$ which is uniformly valid for $3 \leqslant M_{L}$ $\lesssim 7,5 \leqq M_{0} \leqq 71$, and $M_{w} \gtrsim 71$.
\end{abstract}

It is well known that the most widely used earthquake magnitude scales, $M_{L}$ (local magnitude), $M_{0}$ (surface wave magnitude), and $m_{b}$ (body wave magnitude), are, in principle, unbounded from above. It is equally well known that, in fact, they are so bounded, and the reasons for this are understood in terms of the operation of finite bandwidth instrumentation on the magnitude-dependent frequency characteristics of the elastic radiation excited by earthquake sources. Using just these ideas, Hanks [1979] demonstrated how the maximum reported $m_{b} \simeq 7$ and maximum reported $M_{B} \simeq 8.3$ can be rationalized rather precisely. (The upper limit to $m_{b}$ at $\simeq 7$ occurs when $m_{b}$ is determined from body wave amplitudes at periods near $1 \mathrm{~s}$, for example, when $m_{b}$ is determined from World-Wide Standard Seismograph Network (WWSSN) data. Prior to the establishment of the WWSSN in the early 1960's, many $m_{b}$ values were determined from longer-period amplitude measurements, and this is especially so in the case of the larger earthquakes [Geller and Kanamori, 1977]. Many of these older, longerperiod values are considerably greater than 7 ; this period dependence of $m_{b}$ is also understood in terms of frequencydependent source excitation.) Similarly, the maximum $M_{L}$ reported in southern California after more than 40 years of magnitude determination is 6.8 [Hileman et al., 1973], the values of 7.1 for the earthquake of December 31, 1934, and 7.7 for the Kern County earthquake of July 21, 1952, listed there being $M_{\text {g. }}$. Although Kanamori and Jennings [1978] have obtained $M_{L}$ slightly larger than 6.8 by synthesizing Wood-Anderson seismograms from available strong-motion accelerograms and Bolt [1978] has recently determined $M_{L}=7.2$ for the Kern County earthquake from distant stations, it seems likely that the upper limit to $M_{L}$ is also near 7 , principally because $m_{b}$ and $M_{L}$ are both obtained from amplitudes at $\sim 1-\mathrm{s}$ period and because of the form of the correlation between $m_{b}$ and $M_{L}$ [Gutenberg and Richter, 1956].

Thus the magnitude scales $M_{L}, M_{s}$, and $m_{b}$ are' said to saturate at large magnitude. Just as in the case of peak acceleration data at a fixed distance $R$ [Hanks and Johnson, 1976; Hanks, 1979], $M_{L}, M_{B}$, and $m_{b}$ for crustal earthquakes saturate for the same physical reason: for large enough earthquakes, all of these narrow-band time domain amplitude measurements no longer measure gross faulting characteristics but only limiting conditions on localized failure along crustal fault zones. Peak acceleration data at $R \simeq 10 \mathrm{~km}$ no more measure gross source properties for an earthquake with seismic moment $M_{0} \gtrsim 10^{25} \mathrm{dyn} \mathrm{cm}$ than does $m_{0}$ or $M_{L}$ for an earthquake of $M_{0}$ $\gtrsim 10^{27} \mathrm{dvn} \mathrm{cm}$ or $M_{\mathrm{s}}$ for an earthquake of $M_{0} \gtrsim 10^{28} \mathrm{dyn} \mathrm{cm}$.

Copyright (c) 1979 by the American Geophysical Union.
Hanks and Thatcher [1972] pointed out that a magnitude scale based directly on an estimate of the radiated energy, rather than the converse, would not only circumvent the difficulties associated with characterizing earthquake source strength with narrow-band time domain amplitude measurements, specifically magnitude saturation, but had become practical with the increased understanding of the gross spectral characteristics of earthquake sources that developed in the early 1970's. Kanamori [1977] realized this possibility by independently estimating the radiated energy $E_{s}$ with the relation

$$
E_{s}=\frac{\Delta \sigma}{2 \mu} M_{0}
$$

where $\Delta \sigma$ is the earthquake stress drop and $\mu$ is the shear modulus, reducing (1) to

$$
E_{\mathrm{s}}=\frac{1}{2 \times 10^{4}} M_{0}
$$

by taking advantage of the constancy of earthquake stress drops for shallow earthquakes [Aki, 1972; Thatcher and Hanks, 1973; Kanamori and Anderson, 1975; Hanks, 1977], and using (2) in the Gutenberg-Richter relation between $E_{s}$ and $M_{s}$

$$
\log E_{s}=1.5 M_{s}+11.8
$$

where $E_{a}$ is in ergs. The idea is that if $M_{a}$ is bounded, so too is $E_{s}$ as obtained from (3), but if $E_{s}$ is known independently from (2), it may be used on the left-hand side of (3) to determine a magnitude $M_{w}$ that will not saturate. A significant feature of Kanamori's [1977] definition of $M_{w}$ by (3) through use of (2) is that he found that $M_{w}$ so defined is quite similar to $M_{s}$ for a number of earthquakes with $M_{a} \lesssim 8$, that is, well below the saturation level of $M_{\mathrm{s}}$. This agreement attests to the general validity of both the Gutenberg-Richter $E_{s}-M_{s}$, relation (3) for $M_{s} \leqslant 8$ and the use of (2) to estimate $E_{s}$ independently.

A second important feature of $M_{w}$ as defined by Kanamori [1977] is that it is intrinsically a moment magnitude scale. This moment magnitude relation is, upon substituting (2) on the left-hand side of (3) and $M_{w}$ for $M_{a}$ on the right-hand side of (3),

$$
\log M_{0}=1.5 M_{w}+16.1
$$

which is remarkably coincident with the $M_{0}-M_{8}$ relationship empirically defined by Purcaru and Berckhemer [1978] for $5 \lesssim$ $M_{\mathrm{s}} \lesssim 7 \mathrm{k}$ :

$$
\log M_{0}=1.5 M_{s}+(16.1 \pm 0.1)
$$

and the $M_{0}-M_{L}$ relationship empirically defined by Thatcher and Hanks [1973] for southern California earthquakes $(3 \leqslant$ 
$\left.M_{L} \lesssim 7\right):$

$$
\log M_{0}=1.5 M_{L}+16.0
$$

Thus a single moment magnitude $\mathbf{M}$ may be written from (4), (5), and (6):

$$
\mathrm{M}=\boldsymbol{j} \log M_{0}-10.7
$$

Apart from the scatter of the observations about the empirically defined relations (3), (5), and (6), $M$ as defined by (7) is uniformly valid with respect to $3 \leqslant M_{L} \leqslant 7,5 \leqslant M_{s} \leqslant 71$, and $M_{w}$ at larger magnitude. To the extent that coda duration magnitudes used extensively for $M_{L} \lesssim 3$ earthquakes are tied to $M_{L}$ [e.g., Lee et al., 1972], $M$ as given by (6) should apply to them as well, although it would be desirable to verify this with $M_{0}$-coda duration data.

Table 1 presents $M_{0}, M_{L}, M_{\theta}$, and $\mathrm{M}$ calculated from (7) for a number of significant southern California earthquakes between 1918 and 1973, and Table 2 presents these parameters, as available, for five large California earthquakes between 1857 and 1906. For the earthquakes between 1918 and 1973, there is, on balance, good agreement between $M_{L}, M_{B}$, and $\mathrm{M}$. In the case of the Imperial Valley (1940) earthquake, $M_{L}$ is 0.6 units less than $M$, revealing anomalously low 1-s ground motion amplitudes for what is otherwise a fairly large earthquake by California standards. In the case of the Kern County (1952) main shock, $M_{L}$ is 0.5 units less than $M_{\theta}$ and 0.3 units less than M, almost certainly reflecting the saturation level of $M_{L}$ around 7. In the case of the Point Mugu (1973) earthquake the large $M_{L}$ relative to $M_{s}$ and $\mathrm{M}$ reflects anomalously large 1-s excitation for an earthquake with such a small $M_{0}$, in turn suggesting a relatively high stress drop [Ellsworth et al., 1973]. Similarly, $M_{L}$ for the Desert Hot Springs (1948) earthquake is

TABLE 1. Seismic Moments and Magnitudes for Southern California

\begin{tabular}{|c|c|c|c|c|}
\hline Date & $\begin{array}{c}M_{0} \\
\times 10^{26} \\
\text { dyn cm }\end{array}$ & $M_{L}$ & $M_{a}$ & $\mathbf{M}$ \\
\hline $\begin{array}{l}\text { April } 21,1918 \\
\text { July } 23,1923 \\
\text { June } 29,1925 \\
\text { Nov. 4, } 1927 \\
\text { March } 11,1933 \\
\text { May } 19,1940 \\
\text { July } 1,1941 \\
\text { Oct. } 21,1942 \\
\text { March } 15,1946 \\
\text { April 10, } 1947 \\
\text { Dec. } 4,1948 \\
\text { July 21, } 1952 \text { (main shock) } \\
\text { July } 21,1952 \text { (aftershock) } \\
\text { July 29, } 1952 \text { (aftershock) } \\
\text { March } 19,1954 \\
\text { April } 9,1968 \\
\text { Feb. 9, } 1971 \\
\text { Feb. } 21,1973\end{array}$ & $\begin{array}{c}15 \\
1 \\
20 \\
100,65^{*} \\
2 \\
30 \\
0.9 \\
9 \\
1 \\
7 \\
1 \\
200 \\
3 \\
3 \\
4 \\
6 \\
10 \\
0.1\end{array}$ & $\begin{array}{l}6.3 \\
6.4 \dagger \\
5.9 \\
6.5 \\
6.3 \\
6.2 \\
6.5 \\
7.2 \ddagger \\
6.4 \\
6.1 \\
6.2 \\
6.4 \\
6.4 \\
5.9\end{array}$ & $\begin{array}{l}6.8 \\
61 \\
61 \\
7.3 \\
6 t \\
6.7 \\
5.9 \\
61 \\
61 \\
6.4 \\
6.5 \pm \\
7.7\end{array}$ & $\begin{array}{l}6.8 \\
6.0 \\
6.8 \\
7.3,7.2 \\
6.2 \\
7.0 \\
6.0 \\
6.6 \\
6.0 \\
6.5 \\
6.0 \\
7.5 \\
6.3 \\
6.3 \\
6.4 \\
6.5 \\
6.6 \\
5.3\end{array}$ \\
\hline
\end{tabular}
Earthquakes (1918-1973)

Unless otherwise specified, $M_{0}$ entries are from Hanks et al. [1975], and $M_{L}$ entries from Hileman et al. [1973]. All but the last three $M_{s}$ entries are from Gutenberg and Richter [1954], taken as $M_{\text {, according }}$ to Geller and Kanamori [1977]. $M$, for April 9, 1968, and February 9 , 1971 , are from Kanamori and Anderson [1975], and $M_{8}$ for February 21, 1973, is from the National Earthquake Information Service, U.S. Geological Survey.

*From Yeh [1975].

†From Trifunac and Brune [1970].

$\ddagger$ From Bolt [1978].
TABLE 2. Seismic Moments and Magnitudes for Some Large

\begin{tabular}{|c|c|c|c|}
\hline Date & $\begin{array}{c}M_{0} \\
\times 10^{25} \text { dyn } \mathrm{cm}\end{array}$ & $M_{0}$ & $\mathbf{M}$ \\
\hline $\begin{array}{l}\text { Jan. } 9,1857 \\
\text { March 26, } 1872 \\
\text { Feb. 9, 1890 } \\
\text { Dec. 25, } 1899 \\
\text { April 18, } 1906\end{array}$ & $\begin{array}{l}900,530-870^{*} \\
500 \\
15 \\
15 \\
400, \dagger 350-430^{*}\end{array}$ & 8独 & $\begin{array}{l}7.9,7.8-7.9 \\
7.8 \\
6.8 \\
6.8 \\
7.7,7.7\end{array}$ \\
\hline
\end{tabular}
California Earthquakes (1857-1906)

Unless otherwise specified, $M_{0}$ entries are from Hanks et al. [1975].

*From Sieh [1977].

†From Thatcher [1975].

$\ddagger$ From Gutenberg and Richter [1954].

0.5 units larger than $\mathbf{M}$, which may again reflect a high stress drop [Thatcher and Hanks, 1973], but $M_{s}$, although it is apparently less well determined, it also larger than $\mathbf{M}$ by the same amount. As is the case for the observational scatter of the moment magnitude pairs from the appropriate empirical relation (i.e., equations (5) or (6)), deviations of $\mathrm{M}$ from $M_{\mathrm{a}}$ or $M_{L}$ can in most cases be attributed to variable stress drop or saturation of $M_{L}$ or $M_{s}$.

There are several interesting features of Table 2, all associated with the three 'great' California earthquakes of the historical record, the Fort Tejon (1857), Owens Valley (1872), and San Francisco (1906) earthquakes. First, none of the earthquakes can be classified as a great earthquake on the $\mathbf{M}$ scale. Kanamori [1977] lists three dozen earthquakes between 1904 and 1969 larger than the San Francisco earthquake, and in fact there are more than this, since the $M_{0}$ given here for this earthquake is approximately $2 \frac{1}{2}$ times smaller than that given by Kanamori [1977]. Second, these three earthquakes all have very similar $M_{0}$ and $\mathrm{M}$, suggesting that an upper limit of $M_{0} \simeq$ $10^{28}$ dyn $\mathrm{cm}$ and $M \simeq 8.0$ may exist for California earthquakes. This upper limit is physically reasonable if, for California earthquakes, the seismogenic depth of faulting does not exceed $15-20 \mathrm{~km}$ and if fault lengths do not exceed several hundred kilometers. Finally, these three earthquakes are only somewhat larger than the Kern County (1952) earthquake, for which close-in instrumental ground motion records are available. While the coverage is far from ideal, the importance of these records for aseismic design practices and the mitigation of other earthquake hazards is obvious enough, if indeed the Kern County earthquake is near the upper limit in source strength for California earthquakes.

Acknowledgments. D. M. Boore, W. R. Thatcher, and R. L. Wesson critically read the manuscript and made several useful suggestions. This research was supported in part by NSF grant ENV 76-81816. Publication approved by the Director, U.S. Geological Survey. Contribution 3187, Division of Geological and Planetary Sciences, California Institute of Technology.

\section{REFERENCES}

Aki, K., Earthquake mechanism, Tectonophysics, 13, 423-446, 1972. Bolt, B. A., The local magnitude $M_{L}$ of the Kern County earthquake of July 21, 1952, Bull. Seismol. Soc. Amer., 68, 513-515, 1978.

Ellsworth, W. L., R. H. Campbell, D. P. Hill, R. A. Page, R. W. Alewine, T. C. Hanks, T. H. Heaton, J. A. Hileman, H. Kanamori, B. Minster, and J. H. Whitcomb, Point Mugu, California, earthquake of 21 February 1973 and its aftershocks, Science, 182, 1127$1129,1973$.

Geller, R. J., and H. Kanamori, Magnitudes of great shallow earthquakes from 1904-1952, Bull. Seismol. Soc. Amer., 67, 587-598, 1977.

Gutenberg, B., and C. F. Richter, Seismicity of the Earth, 2nd ed., 310 pp., Princeton University Press, Princeton, N. J.. 1954. 
Gutenberg, B., and C. F. Richter, Magnitude and energy of earthquakes, Ann. Geofis., 9, 1-15, 1956.

Hanks, T. C., Earthquake stress drops, ambient tectonic stresses and stresses that drive plate motions, Pure Appl. Geophys., 115, 441-458, 1977.

Hanks, T. C., $b$-values and $\omega^{-\gamma}$ seismic source models: Implications for tectonic stress variations along active crustal fault zones and the estimation of high-frequency strong ground motion, $J$. Geophys. Res., this issue, 1979.

Hanks, T. C., and D. A. Johnson, Geophysical assessment of peak accelerations, Bull. Seismol. Soc. Amer., 66, 959-968, 1976.

Hanks, T. C., and W. Thatcher, A graphical respresentation of seismic source parameters, J. Geophys. Res., 77, 4393-4405, 1972.

Hanks, T. C., J. A. Hileman, and W. Thatcher, Seismic moments of the larger earthquakes of the southern California region, Geol. Soc. Amer. Bull. 86, 1131-1139, 1975.

Hileman, J. A., C. R. Allen, and J. M. Nordquist, Seismicity of the southern California region 1 January 1932 to 31 December 1972, report, Seismol. Lab., Calif. Inst. of Technol., Pasadena, 1973.

Lee, W. H. K., R. E. Bennet, and K. L. Meahger, A method of estimating magnitude of local earthquakes from signal duration, open file report, U.S. Geol. Surv., Menlo Park, Calif., 1972.

Kanamori, H., The energy release in great earthquakes, J. Geophys. Res., 82, 2981-2987, 1977.
Kanamori, H., and D. L. Anderson, Theoretical basis of some empirical relations in seismology, Bull. Seismol. Soc. Amer., 65, 10731096, 1975.

Kanamori, H., and P. C. Jennings, Determination of local magnitude, $M_{L}$, from strong-motion accelerograms, Bull. Seismol. Soc. Amer., 68, 471-485, 1978.

Purcaru, G., and H. Berckhemer, A magnitude scale for very large earthquakes, Tectonophysics, 49, 189-198, 1978.

Sieh, K. E., A study of Holocene displacement history along the south-central reach of the San Andreas fault, Ph.D. thesis, Stanford Univ., Stanford, Calif., 1977.

Thatcher, W., Strain accumulation and release mechanism of the 1906 San Francisco earthquake, J. Geophys. Res., 80, 4862-4880, 1975.

Thatcher, W., and T. C. Hanks, Source parameters of southern California earthquakes, J. Geophys. Res., 78, 8547-8576, 1973.

Trifunac, M. D., and J. N. Brune, Complexity of energy release during the Imperial Valley, California, earthquake of 1940, Bull. Seismol. Soc. Amer., 60, 137-160, 1970.

Yeh, H.-C., Mechanism of the 1927 Lompoc earthquake from surface wave analysis, M.S. thesis, Univ. of Wash., Seattle, 1975.

(Received August 22, 1978; revised December 20, 1978; accepted January 8, 1979.) 